\title{
FORMAÇÃO DOCENTE E ENSINO DE LÍNGUA POR- TUGUESA EM TIMOR-LESTE: considerações de professores brasileiros
}

Joice Eloi Guimarães

Universidade Estadual de Campinas Hankuk University of Foreign Studies

\section{RESUMO}

Em 2002, após o processo de restauração da independência, a República Democrática de Timor-Leste elegeu como línguas oficiais e de instrução a língua portuguesa e a língua tétum. No processo de (re)introdução do português nas diversas esferas sociais do país atuaram, por meio do Programa de Qualificação Docente e Ensino de Língua Portuguesa em Timor-Leste (PQLP/CAPES), professores brasileiros de diferentes áreas do conhecimento. Desse conjunto de docentes, selecionamos, para participar deste trabalho, aqueles cuja prática em Timor era voltada ao ensino da língua portuguesa. Os dados coletados, por meio de instrumento de questionário, são enunciados escritos acerca da formação e da docência desses sujeitos. A metodologia utilizada para análise dos dados fundamenta-se nos estudos desenvolvidos por Bakhtin $(2010 ; 2011)$. Pela teoria do dialogismo, elegemos como categorias de análise dos enunciados conceitos componentes do contexto extraverbal de sua produção: conceito de cronotopo - tempo (histórico) e espaço (social) - e de valoração, avaliação social do sujeito que enuncia em relação ao objeto sobre o qual ele enuncia. De forma geral, a análise realizada permite entrever a existência de lacunas na formação dos professores para atuação em Timor-Leste e, o reconhecimento, por parte desses sujeitos, da importância do uso da língua tétum e de aspectos da cultura timorense no ensino de português no país.

PALAVRAS-CHAVE: Língua Portuguesa. Timor-Leste. Ensino. Formação docente. 


\section{Introdução}

A língua portuguesa, doravante LP, em Timor-Leste tem uma história de mais de 500 anos. Língua introduzida pelo colonizador, Portugal, esteve presente no país até o ano de 1975, quando houve a invasão pela vizinha Indonésia e a obrigatoriedade do uso da língua indonésia, juntamente com a proibição da LP. Após o processo de Restauração da Independência de Timor, em 2002, as autoridades timorenses decidiram recuperar o idioma da antiga potência administrativa. Desde então, o português passou a configurar como língua oficial e de instrução ao lado da língua tétum - língua veicular utilizada cotidianamente pelos timorenses possuidores de diferentes línguas maternas.

A efetivação de tal medida de política de língua requereu - e requer ainda - ações de (re)introdução do português nas mais diversas esferas de organização da sociedade timorense (ALMEIDA, 2012). Para tanto, o governo de Timor-Leste conta com a parceria da comunidade internacional, sobretudo dos países integrantes da Comunidade de Países de Língua Portuguesa (CPLP). Na área educacional, o Brasil realizou ações em Timor de 2004 a 2016 por meio do Programa de Qualificação Docente e Ensino de Língua Portuguesa em Timor-Leste (PQLP/CAPES). Durante esse período, anualmente professores brasileiros eram enviados a Timor para atuação, sobretudo, nas áreas de formação de professores, de ensino de LP e de apoio ao ensino superior no país. Entretanto, para o desenvolvimento de sua prática, ao chegarem em Timor, esses docentes deparavam-se com um contexto multilíngue específico, em que o português não é língua materna da maioria dos timorenses.

Considerando esse contexto, neste trabalho realizamos uma análise enunciativo-discursiva dos enunciados produzidos por docentes brasileiros acerca de sua experiência com o ensino da LP em Timor-Leste. Utilizamos, nesse intuito, os estudos do filósofo russo Mikhail Bakhtin e de integrantes do seu Círculo. Dessa linha teórica elegemos como critérios de análise dos enunciados componentes do contexto extraverbal de sua produção - conceito de cronotopo e de valoração. Com base nesses conceitos, propomos, neste estudo, uma discussão acerca dos temas concernentes ao ensino de LP e à formação docente em contextos de português como língua não materna.

Para tanto, este trabalho está organizado da seguinte forma: na próxima seção, contextualizamos brevemente a presença da LP em Timor- 
-Leste e sua característica de língua não materna nesse país. Em seguida, apresentamos o Programa de Qualificação de Docente em Língua Portuguesa em Timor-Leste (PQLP/CAPES). Após, discorremos sobre o embasamento teórico-metodológico que norteia nosso olhar sobre os dados, bem como os caminhos percorridos para o desenvolvimento desta pesquisa. Por fim, são realizadas as etapas de interpretação e análise dos dados e apresentadas algumas considerações.

\section{Língua Portuguesa em Timor-Leste: ensino de língua não materna}

As línguas são portadoras de referência à identidade, à ação e à memória dos grupos que as compartilham. Constituem-se, desse modo, como vetores dos bens culturais materiais e imateriais produzidos por um povo, e, ainda, elas mesmas como bens a serem preservados. Em Timor-Leste observamos a coexistência de línguas que, devido a fatores histórico-sociais, perduram na sociedade timorense - as línguas oficiais: o tétum e o português; as línguas de trabalho: a língua indonésia e a língua inglesa e; as línguas autóctones, que variam em número (entre 15 e 31) de acordo com a fonte pesquisada (SOARES, 2014). O português em meio a essa babel linguística é, em geral, a terceira ou quarta língua que os timorenses adquirem. Constitui-se, portanto, como língua não materna para esses sujeitos.

Como língua não materna compreendemos àquela que se contrapõe à língua materna, ou seja, a que é aprendida como primeiro instrumento de comunicação e estabelece relações sociais, afetivas etc. entre o sujeito que a adquire e o contexto em que está inserido. Situando nossa discussão no contexto de ensino e aprendizagem de língua não materna, com base nas reflexões desenvolvidas por Bakhtin [Volochínov] (2010, p. 102) acerca da relação signo linguístico e sinal, podemos inferir que, no uso que os sujeitos fazem de uma língua não materna, a compreensão do signo linguístico - enquanto material ideológico que reflete e refrata algo, torna-se um desafio, pois "Não se trata de uma reflexão sobre a percepção que o locutor nativo tem de sua própria língua; trata-se, antes, da reflexão de uma consciência que luta para abrir caminho no mundo misterioso de uma língua estrangeira".

As nomenclaturas língua estrangeira, língua segunda, língua adicional, entre outras, são contempladas na definição de língua não materna. De acordo com a tipificação de conceitos elaborada por Almeida 
Filho (2005) a partir de semelhanças que se estabelecem historicamente entre diferentes contextos de uso e ensino de línguas, entendemos, neste trabalho, o ensino de LP em Timor-Leste, como ensino de língua segunda, devido a sua característica de língua oficial em que há um "contato estreito entre duas línguas num mesmo espaço e numa dada relação de poder mantida temporária ou perenemente" (ALMEIDA FILHO, 2005, p.6). O ensino de português nesse contexto, segundo o autor, pode se dar: por submersão, a LP fazendo submergir outras LS; por transição, processo em que o aprendente vai passando de uma língua local para a LP e; por co-existência, em que a LP atua como apoiadora tolerante de outras línguas que estiverem em contato.

Parece-nos que as diretrizes curriculares atuais de Timor-Leste preconizam o ensino de LP no país em uma relação de coexistência com as demais línguas presentes no território leste-timorense. Isso porque, nesses documentos, faz-se presente a importância da(s) língua(s) que o aluno domina no processo de aquisição/desenvolvimento de outras línguas, como o português. Sendo assim, as demais línguas que integram o repertório linguístico dos alunos participam desse processo, em um plano de progressão linguística, que tem início no pré-escolar, com a utilização da língua tétum e das demais línguas maternas, e culmina no $3^{\circ}$ ciclo do ensino básico, a sobreposição da disciplina de Língua Portuguesa em relação à Língua Tétum. De acordo com o Decreto-Lei 4/2015, Artigo 14²:

É garantida uma progressão gradual do Tetum ao Português, de modo a que esta última constitua a principal língua objeto da literacia e de instrução no terceiro ciclo do ensino básico, e que, no final do ensino básico, os alunos tenham adquirido um nível semelhante de conhecimento de ambas as línguas oficiais.

A multiplicidade linguística em que estão imersos alunos e professores está presente no contexto escolar, nas interações que ali se desenvolvem. Ou seja, a escola, enquanto espaço de socialização, repercute a multiplicidade que constitui, em parte, o repertório linguístico dos timorenses (SOARES, 2014). Além da coexistência de várias línguas no país, observamos, também, a presença de mais de uma variedade do português - principalmente as variedades europeia e brasileira, além da variedade que sofre interferência da língua materna do aluno timorense (ALBUQUERQUE, 2010), o que acentua o desafio que é a docência em/de LP em Timor. Nesse sentido, conforme Almeida (2004), perante um grupo de pessoas que 
quer aprender outra língua, é importante que o professor tenha consciência das razões que levam a que esse conjunto de pessoas a queira aprender.

Esses elementos histórico-sociais, concernentes do contexto extraverbal da linguagem, estão fora do sistema linguístico, mas participam ativamente da produção dos enunciados quando o tema é a LP em solo timorense. Dessa forma, tais elementos tomam parte significativa dos processos de ensino e aprendizagem de português em Timor e precisam ser considerados, sobretudo, pelos sujeitos que intentam ensinar essa língua.

Nesse sentido, é importante levar em conta a característica de estrangeiros dos professores brasileiros atuantes no processo de (re)introdução da LP em Timor. Ou seja, agentes culturais externos, característica que certamente impregna uma influência nas referências culturais dos alunos, afinal o ensino de uma língua comporta diferentes matrizes ideológicas, identitárias e culturais, já que uma mesma língua é representada por diferentes línguas-culturas. (MENDES, 2015). O professor que ensina a LP em Timor-Leste tem de estar ciente disso, caso contrário corre $\mathrm{o}$ risco de, ao ensinar a LP, inserir valores, padrões etc., ignorando aqueles presentes no país. É preciso lembrar sempre que o ensino de LP em Timor é voltado para o uso dessa língua em solo timorense, em meio à cultura e às demais línguas desse povo.

Pela estreita ligação da língua pela cultura, o plurilinguismo é potenciador do desenvolvimento de uma competência intercultural [...] Neste sentido, porque está na base do desenvolvimento de valores de cidadania, a ativação de uma competência intercultural, através do desenvolvimento da competência plurilíngue, torna-se uma possibilidade a explorar no cenário babélico timorense. (ALMEIDA, 2012, p. 861).

Com base nesse entendimento, cabe pensarmos no papel da LP em Timor-Leste não fundida nela mesma, mas, sobretudo, como meio de acesso e preservação das demais línguas que coexistem no país, em uma relação de complementaridade e não de concorrência.

\section{0 Programa de Qualificação de Docente e Ensino de Língua Portuguesa em Timor-Leste (PQLP/CAPES)}

O Programa de Qualificação de Docente e Ensino de Língua Portuguesa em Timor-Leste (PQLP/CAPES) realizou ações em solo leste-timorense entre os anos de 2004 e 2016. De acordo com informações extraídas do ambiente virtual do programa ${ }^{1}$, 
O PQLP - Programa de Qualificação de Docente e Ensino de Língua Portuguesa no Timor-Leste é administrado conjuntamente pela Coordenação de Aperfeiçoamento de Pessoal de Nível Superior (CAPES), pela Universidade Federal de Santa Catarina (UFSC) e pelo Departamento Cultural (DC) do Ministério das Relações Exteriores (MRE), e constitui atividade de cooperação educacional exercida com países em desenvolvimento com os quais o Brasil mantém Acordo de Cooperação Educacional, Cultural e de Ciência e Tecnologia.

No desenvolvimento das ações em Timor, o PQLP, por meio de chamada pública, selecionou professores brasileiros de todas as áreas do conhecimento para desenvolver diversas ações direcionadas aos objetivos do programa, os quais estavam ancorados nos seguintes eixos temáticos: a) formação inicial e continuada dos docentes; b) fomento ao ensino da língua portuguesa e; c) apoio ao ensino superior.

De acordo com os dois últimos editais do programa, que abarcam a seleção dos professores participantes desta pesquisa, dentre as obrigações do candidato selecionado constavam o desenvolvimento de cursos de português como segunda língua para profissionais de diferentes áreas e níveis de proficiência e a elaboração e revisão de materiais didáticos apropriados ao tipo e nível de curso ministrado. Observamos que, dentre as obrigações do candidato, consta a característica da LP como segunda língua em contexto timorense.

Entretanto, tal característica não era item fundamental constante na formação dos sujeitos que intentassem realizar a candidatura. Nos requisitos para a candidatura presentes no Edital 076/2013, solicitava-se que o candidato atendesse ao menos um dos itens abaixo:

2.1.1. Estudantes brasileiros de cursos de pós-graduação stricto sensu em educação, educação científica e tecnológica, ensino de ciências, ensino de língua portuguesa, linguística e/ou áreas afins, preferencialmente com no mínimo dois anos de experiência docente comprovada na área;

2.1.2. Docentes brasileiros de Instituições de Ensino Superior (IES) com no mínimo dois anos de experiência em ensino, pesquisa e/ou extensão nas áreas de educação, educação científica e tecnológica, ensino de ciências, ensino de língua portuguesa, linguística e áreas afins;

2.1.3. Integrantes brasileiros de projetos de pesquisa ou núcleos de estudos nas IES, com pós-graduação stricto sensu e experiência de no 
mínimo dois anos em docência, pesquisa e/ou extensão nas áreas de interesse deste Edital;

2.1.4. Professores brasileiros com experiência comprovada na elaboração e atuação na formação de professores nas redes da Educação Básica;

2.1.5. Professores brasileiros com experiência comprovada no ensino de língua portuguesa como língua estrangeira que possuam pós-graduação stricto sensu ou que estejam vinculados a projetos de pesquisa na área da linguística ou educação. (EDITAL 076/2013, 1, grifos no original).

Conforme as informações presentes neste edital, a experiência com a docência é item fundamental para a seleção dos professores para atuação em Timor-Leste. Contudo, apenas no último item presente no Edital há a menção ao ensino de língua portuguesa como língua estrangeira. Vale ressaltar aqui a definição de língua estrangeira (LE) cunhada por Almeida Filho (2005, p. 6), "LE não conta tradicionalmente com o contato social próximo, interativo e generalizado com uma L1 predominante". Com base no entendimento desse autor, não nos é possível classificar a LP em Timor-Leste como língua estrangeira, haja vista o contato com essa língua nos ambientes de ensino e nas esferas administrativas e políticas, além do constante contato com a língua tétum.

Ainda com base nas informações presentes no Edital, no que diz respeito aos requisitos para candidatura dos professores, podemos afirmar que não havia, por parte do PQLP, uma preocupação em selecionar professores com reconhecida experiência de atuação em contextos de ensino de português como língua não materna, já que a experiência com ensino de LE não era item obrigatório. Há no Edital, uma preocupação que o candidato possua alguma experiência com formação de professores e/ou docência, sem especificar em que contextos de ensino de língua. Nesse sentido, cabe a pergunta: os professores com experiência em ensino de língua materna estão aptos a ensinar essa mesma língua em um contexto em que ela não é a língua materna dos sujeitos em aprendizagem?

Em relação aos aspectos concernentes à formação com vistas à realização do trabalho didático em Timor-Leste, os cooperantes que foram selecionados no último Edital do programa receberam, na chegada ao solo timorense, um curso intensivo de língua tétum, com duração de 01 semana. A importância do conhecimento da língua utilizada pelos sujeitos em 
aprendizagem está presente no Projeto Político Pedagógico do Programa, documento elaborado pelos professores enquanto estavam em Timor-Leste. Nesse documento, faz-se presente a importância de um plano de formação inicial e contínua que dê conta das necessidades apontadas pelos professores brasileiros (PPP/PQLP, 2014), como o conhecimento e uso da língua tétum.

O tétum é veículo de comunicação entre os timorenses na cidade de Díli e, muitas vezes, é o único recurso para o contato com os estrangeiros (para aqueles timorenses que não falam português ou alguma língua estrangeira). Dessa forma, no que diz respeito às práticas de ensino, o uso dessa língua pode tornar-se uma ferramenta importante para o professor compreender e fazer-se compreender em sala de aula. Certamente, o uso do tétum também contribui para o acesso a outras práticas sociais em Timor-Leste. (PPP/PQLP, 2014: 52).

As considerações desses docentes vão ao encontro do que aponta Ançã (1999, n.p.):

É inegável que o conhecimento do funcionamento da língua materna do aluno ou do grupo linguístico a que pertence [...] é um apoio importante. Este conhecimento não implica que o professor fale fluentemente essa e outras línguas, mas que saiba reconhecer as zonas conflituosas (sintácticas, léxico-culturais, etc.), a fim de encaminhar o aluno a ultrapassar as suas dificuldades específicas.

Além da formação em língua tétum, os professores selecionados no processo seletivo regido pelo Edital 076/2013 receberam também formações com cooperantes que já estavam em Timor para esclarecer dúvidas em relação a aspectos culturais e educativos do país e às atividades desenvolvidas pelo programa. Além disso, contaram, durante o período de trabalho no país, com encontros realizados em grupos de estudos entre os cooperantes e formação com professores timorenses para favorecer a compreensão da realidade local a partir da visão dos nativos.

Ressaltamos que os aspectos abordados nessas formações são de extrema importância para a prática dos professores. No entanto, percebemos, de antemão, uma lacuna no que diz respeito aos aspectos metodológicos referentes ao ensino de português no contexto de Timor-Leste, principalmente se consideramos que a formação específica com ensino de uma língua não materna não constava no Edital como requisito fundamental para a seleção dos professores. 


\section{Fundamentação teórico-metodológica - Cami- nhos da pesquisa}

A metodologia utilizada nesta pesquisa é de abordagem sócio-histórica e orienta-se pela teoria do dialogismo desenvolvida por Bakhtin e demais autores integrantes de seu Círculo. Nessa linha teórica o conceito de dialogismo, fundamentado na relação eu x outro, configura-se como uma forma de compreender e dar sentido às ações humanas inseridas em um tempo histórico e um espaço social. Com base nesse princípio, o diálogo, mais especificamente as relações dialógicas, ocupa posição precípua para a busca do entendimento do enunciado concreto no grande diálogo da cadeia da comunicação discursiva humana. $\mathrm{O}$ enunciado é um acontecimento entre sujeitos; é comunicação verbal dialógica, social, histórica e ideológica. Por essa razão, o enunciado como unicidade concreta (real) da comunicação humana possibilita a compreensão da atividade do homem.

Para realização deste estudo, no qual objetivamos analisar os enunciados de professores integrantes do PQLP sobre a realização da prática pedagógica em Timor-Leste, elegemos, como categorias para nossa análise, alguns conceitos que alicerçam a teoria do dialogismo: conceito de cronotopo (horizonte temporal e espacial - tempo (histórico) e espaço (social); e valoração (elemento axiológico do enunciado; a avaliação social do sujeito que enuncia em relação ao objeto sobre qual ele enuncia).

O espaço-tempo em que se dá a prática dos integrantes desta pesquisa é a aula de LP realizada em instituições oficiais de ensino de Timor-Leste, em período de (re)introdução dessa língua nos currículos escolares. As relações sociais que se dão nesse contexto específico refletem e refratam enunciados, os quais são o alvo de nossa análise. Para levá-la a efeito, o conceito de cronotopia desenvolvido por Bakhtin apresenta-se como fundamento, pois, segundo o autor, a inter-relação do espaço-tempo é elemento que integra o enunciado desde o interior.

A inter-relação do cronotopo com a produção dos enunciados não se dá de maneira evidente, pois nos diferentes cronotopos em que os enunciados são proferidos estão presentes vozes sociais. Essas vozes configuram-se como representantes das ideologias de grupos sociais específicos em determinados tempos e espaços históricos e atuam, portanto, de modos distintos no processo de construção dos enunciados. Nesse processo, os enunciados encontram-se imersos no embate entre posições valorativas que agem na sua constituição. Sendo assim, o enunciado, como 
acontecimento ideológico, "possui sempre um índice de valor social" (Bakhtin [Volochínov] 2010, p. 46). A relação dos professores com a prática pedagógica que desenvolvem em Timor está, portanto, intimamente ligada à valoração que eles atribuem a presença da LP no país.

O espaço-tempo em que se dá o desenvolvimento da presente pesquisa, bem como a valoração do sujeito que enuncia sobre o que ele enuncia, está relacionado e imbricado no todo dos enunciados, alvos de nossa análise. Sendo assim, nossa análise recai sobre os sentidos dos enunciados produzidos por docentes brasileiros quando o tema é a docência que realizam com a LP em Timor-Leste.

$\mathrm{O}$ instrumento utilizado para coleta dos enunciados dos professores foi o questionário com perguntas abertas e fechadas que versavam sobre a formação docente e atuação em Timor-Leste. Dessa forma, nosso corpus de análise é constituído de enunciados escritos. Aplicamos o questionário a todos os cooperantes da área de LP que atuaram no PQLP nos anos de 2014 e 2015. Dos 17 cooperantes que se enquadravam nesse perfil, 14 responderam ao questionário.

Em relação à formação inicial desses docentes, 09 são graduados em Letras-Língua Portuguesa (sendo que um deles tem graduação em Pedagogia também), 01 em Letras-Espanhol, 02 em Letras-Habilitação em Língua Portuguesa e Língua Inglesa, 02 em Letras-Habilitação em Língua Portuguesa e Língua Espanhola. Observamos que a maioria desses professores tem formação em LP como língua materna e aqueles que possuem formação em alguma língua estrangeira, essa língua não é o português.

Abaixo apresentamos, na Tabela 01, as informações referentes à especialização e cursos de Pós-Graduação desses professores: 


\begin{tabular}{|l|l|l|l|l|l|}
\hline $\begin{array}{l}\text { E s p e c i a liz a ç ã o } \\
\text { (área) }\end{array}$ & Prof.s & $\begin{array}{l}\text { Mes tra do } \\
\text { (área) }\end{array}$ & Prof.s & $\begin{array}{l}\text { Dou tora- } \\
\text { do }\end{array}$ & Prof.s \\
\hline $\begin{array}{l}\text { Metodologia de En- } \\
\text { sino de Língua Por- } \\
\text { tuguesa e L í g u a } \\
\text { Estrangeira }\end{array}$ & 01 & Letras & 04 & $\begin{array}{l}\text { Ling uí s- } \\
\text { tica }\end{array}$ & 02 \\
\hline $\begin{array}{l}\text { Letras Português e } \\
\text { Espanhol }\end{array}$ & 01 & Linguística & 03 & & \\
\hline $\begin{array}{l}\text { Ensino de Língua } \\
\text { Portuguesa }\end{array}$ & 04 & $\begin{array}{l}\text { Linguística } \\
\text { Aplicada }\end{array}$ & 01 & & \\
\hline Estudos Literários & 02 & $\begin{array}{l}\text { Estudos } \\
\text { Literários }\end{array}$ & 03 & & \\
\hline Total & 08 & & 11 & & 02 \\
\hline
\end{tabular}

Tabela 01: Cursos de Especialização e Pós-Graduação dos professores.

De acordo com as informações constantes na Tabela 01, apenas um professor possui especialização em metodologia para o ensino de LP como língua estrangeira. Nas demais indicações não é possível precisar se as formações se referem à LP (como língua materna ou língua não materna) ou a outra língua estrangeira.

Em relação à formação contínua para o trabalho com ensino de língua não materna e a experiência docente nessa área, apresentamos o perfil dos professores na Tabela 02 :

\begin{tabular}{|l|l|l|l|}
\hline $\begin{array}{l}\text { Formação voltada ao } \\
\text { ensino de LP como lín- } \\
\text { gua não materna }\end{array}$ & Professores & $\begin{array}{l}\text { Experiência com } \\
\text { ensino de LP como } \\
\text { língua não mater- } \\
\text { na }\end{array}$ & Professores \\
\hline Já tiveram & 04 & De até 1 ano & 04 \\
\hline Não tiveram & 10 & De 1 a 5 anos & 05 \\
\hline & & Não tiveram & 05 \\
\hline
\end{tabular}

Tabela 02: Formação e experiência em ensino de Língua Portuguesa como língua não materna. 
Observamos, com base nas informações presentes na Tabela 02, que a maioria dos professores não teve formações voltadas ao ensino de língua não materna. Apenas 04 responderam afirmativamente e, desses, não é possível precisar se essa formação foi voltada ao ensino de LP como língua não materna. Em relação à experiência didática nessa área, 05 professores afirmaram não possuir experiência, enquanto 09 disseram possuir. Contudo, se considerarmos o tempo de permanência desses docentes em Timor, podemos inferir que aqueles que afirmaram ter experiência de até 01 ano, essa experiência refere-se ao período de trabalho em Timor-Leste, o que reduz o número de professores com essa experiência que iniciaram seu trabalho no país a 05 (sem podermos precisar no ensino de que língua não materna essa experiência foi constituída).

\section{Diálogo com os enunciados dos professores}

Para desenvolver o papel social de docente, o professor parte de um conhecimento teórico-prático. Esse conhecimento é construído, historicamente, nas interações do sujeito professor com a realidade circundante e na percepção que o professor tem das relações sociais e verbais concretas de que participa - aquelas que se dão na esfera escolar ou em outra esfera da atividade humana.

As respostas obtidas por meio do questionário ratificam a importância do conhecimento da língua tétum apontada pelos cooperantes no Projeto Político Pedagógico do Programa e ressaltam que o conhecimento da LP é insuficiente para o trabalho pedagógico em Timor-Leste. Os professores integrantes desta pesquisa afirmaram fazer uso de outras línguas para auxiliar o entendimento dos timorenses com a LP. A língua tétum foi citada por todos os professores, e a língua inglesa por 06 deles. Abaixo apresentamos trechos desses enunciados, os quais foram reproduzidos aqui tal qual constam no original:

Professor 1: Conhecer a estrutura da língua materna do aluno ou da língua utilizada cotidianamente por ele facilita as explicações. É possivel compreender melhor como o aluno se utiliza da LP, quais são suas dificuldades ou os desafios que enfrentará durante a aprendizagem da nova língua.

Professor 2: O professor de LP deve conhecer a língua tétum (não diria língua materna, já que muitos não têm a língua tétum como língua 
materna, mas que todos são falantes da mesma), diante do contexto multilingue de Timor-Leste, articular essa língua veicular ao aprendizado da LP pode ser uma ferramenta importante para o processo de ensino-aprendizagem.

Os enunciados apresentam sempre uma dimensão avaliativa e expressam um posicionamento social. A noção de valoração está intrinsecamente ligada à de ideologia. Pensando na importância dada pelos docentes ao conhecimento da língua tétum para a obtenção do conhecimento linguístico em LP para além das fronteiras linguísticas, vemos que seus enunciados representam um posicionamento político-ideológico de negação à imposição de uma língua - e a cultura que ela carrega - sobre a outra. Essa observação pauta-se no cronotopo específico de produção dos enunciados desses docentes: as aulas de LP realizadas em solo timorense em momento que simbolicamente encerra um período de dominação linguística e de demais elementos da sociedade timorense pela Indonésia.

Observamos que os enunciados dos docentes valoram positivamente a promoção e a valorização das línguas e cultura originariamente timorenses. Podemos inferir que os enunciados dos professores ancoram-se predominantemente nos princípios de liberdade e de autonomia do povo timorense. Esses princípios ressoam enunciados já formulados, cuja interpretação é possível pela sua já incorporação à memória discursiva social. Ao ser proferido, o discurso é orientado para algo já conhecido dos interlocutores. Essas valorações, "não costumam se enunciar, posto que formam parte da carne e do sangue de todos os representantes de um grupo dado" (VOLOCHÍNOV; BAKHTIN, 2011, p. 158). Segundo Bakhtin [Volochínov] (2010), o pertencimento dos sujeitos a um mesmo grupo social (no caso os professores), em uma mesma época, proporciona a esses sujeitos um horizonte social comum, o qual está repleto de valorações subentendidas que organizam as enunciações dos sujeitos integrantes desse grupo social desde seu interior. Assim, observamos que a valoração do sujeito em relação ao objeto sobre o qual ele enuncia - elemento constitutivo do enunciado - reflete determinadas construções ideológicas que pairam na sociedade e que ali permanecem como "valorações subentendidas".

A posição expressa nos enunciados dos professores brasileiros repercute nas necessidades que esses sujeitos apontam para que o trabalho com a LP em Timor-Leste respeite as especificidades do país e promova uma LP que os timorenses se identifiquem. 
Professor 3: É necessário, antes de mais nada, que a LP de Timor tenha suas características linguísticas como qualquer país que a tenha como idioma de fala.

Professor 4: Acho que o ensino de LP deve proporcionar aos timorenses a oportunidade de ampliar os conhecimentos gerais, de ampliar os horizontes deles.

Conforme aponta Bakhtin (2011, p. 369): "O ponto de vista é cronotópico e abrange tanto o elemento espacial quanto temporal", ou seja, o cronotopo de produção dos enunciados comporta aquilo que é conjuntamente partilhado, o que está diretamente relacionado ao que se pode compreender comumente entre os interlocutores. Tal relação produz aquilo que é majoritariamente avaliado no horizonte axiológico/valorativo da situação extraverbal.

Os enunciados dos docentes do PQLP, no tempo e espaço em que são produzidos, possuem sentidos construídos em inter-relação com esse contexto específico e valoram positivamente a importância de não subjugar a(s) língua(s) e a cultura de Timor. O sujeito do dizer assume sua posição de sujeito, identificando-se com a realidade que vivencia. O conteúdo da sua experiência, incorporado a sua constituição enquanto sujeito social, entra em relação direta com sua posição avaliativa.

Ao solicitarmos que os docentes descrevessem um cenário de um curso de formação continuada ideal para um professor que irá atuar em Timor-Leste as respostas se aproximam pela temática que abordam: a importância do conhecimento de aspectos específicos de Timor (língua cultura etc.) e do conhecimento metodológico para o ensino de LP como língua não materna. Os enunciados dos sujeitos descritos abaixo, portanto, são impregnados dos sentidos que se lhes atribuem na dimensão do pequeno tempo, no espaço de atuação em Timor-Leste, e também no diálogo com as experiências que os constituem.

Professor 5: Penso que a formação continuada deva propiciar conhecimento da língua materna, da cultura e da história de Timor. Além disso, é preciso que a teoria que embasa a prática de ensino esteja de acordo com um ensino para o cenário timorense. 
Professor 6: Um curso que envolva o conhecimento da realidade timorense, tanto da cultura, costumes e tradições quanto do ensino em todos os seus níveis.

Professor 7: Estudo do contexto sócio-histórico-linguístico de Timor, estudos sobre multiculturalismo e interculturalidade.

A importância de eventos de formação com professores timorenses foi citada apenas por um cooperante. Considerando que todos ressaltam a interação e envolvimento com os nativos e sua cultura como fator importante no desenvolvimento do trabalho em Timor, há que se pensar na ausência de sugestões dessa natureza. Diante disso cabe a pergunta: não estariam os docentes brasileiros, em sua posição de ensinar, ignorando o que os timorenses podem ensiná-los? Ou seja, não estariam esses sujeitos reafirmando na memória comum a importância de adentrar a realidade timorense, mas, ao mesmo tempo materializando, nos subentendidos de seus discursos, o olhar do colonizador perante o colonizado?

No Projeto Político Pedagógico do PQLP, elaborado pelos professores atuantes em Timor-Leste, consta a importância de eventos de formação com professores timorenses. Além disso, como vimos, em relação à formação disponibilizada aos professores brasileiros que chegaram a Timor em 2014 houve encontros de formação com os docentes timorenses. Contudo, se atentarmos para a relação língua/cultura, a pouca participação de professores timorenses nos momentos de formação dos cooperantes do PQLP (no período anterior a chegada no país e durante o período de trabalho) e a ausência dela nos enunciados dos docentes, apresenta-se como uma lacuna, haja vista que o professor timorense tem maior dimensão do papel da LP em seu país e está mais apto a descobrir a forma de encaixar a LP em sua cultura. (ALMEIDA, 2012).

Ao lado da lacuna acima citada (observada a partir do silenciamento dos docentes em relação ao tema) percebemos, nos enunciados referentes às necessidades formativas desses sujeitos para a realização do trabalho em Timor, a valoração positiva de eventos de formação que contemplem aspectos metodológicos referentes ao ensino de uma língua não materna.

Professor 8: Na minha opinião, precisaria ter uma parte voltada para a aprendizagem do tétum, um módulo sobre ensino de LP como língua estrangeira, segunda língua, lingua adicional, entre outras. 
Professor 9: Enfocar principalmente os conceitos de língua estrangeira, L2 e língua adicional, língua veicular e língua de trabalho.

Professor 10: Estudo sobre as abordagens de ensino de PLE.

Observamos nos enunciados acima que os professores brasileiros reconhecem a ausência de uma formação voltada ao ensino de uma língua não materna e, ao mesmo tempo, valoram positivamente a discussão desse tema como elemento que soma a sua atuação em Timor-Leste com o ensino de português. Ressaltamos aqui a importância da formação como um ponto diferenciador e fundamental para o ensino quer no contexto de língua materna quer no de língua não materna (estrangeira ou segunda). Conforme aponta Almeida Filho (2005), para ensinar profissionalmente uma língua não materna, além da formação integral em Letras, é necessária uma formação específica que englobe em seus currículos disciplinas preparatórias para o ensino de língua não materna (PLE ou PLS).

No caso desta pesquisa, essa importância é acentuada, pois a formação específica para o ensino de língua não materna não é um requisito fundamental para a seleção dos professores.

Sabemos que o alcance dos cursos de formação continuada na prática pedagógica dos professores, de modo geral, está na dependência de um conjunto de fatores históricos e sociais que interferem no desenvolvimento de sua prática e na sua constituição como sujeito professor. Em Timor-Leste, esses fatores são linguísticos, como a coexistência de diferentes línguas, a característica de português como língua não materna e desconhecida por parte da população e também fatores extralinguísticos, como a relação histórica e social da LP com o povo timorense e com sua cultura.

Nesse sentido, é preciso que a formação para a prática docente em Timor-Leste seja compreendida como um processo inserido em determinado contexto, no dinamismo próprio da vida que ali se desenvolve, na relação dialógica com o outro, permitindo ao professor exercitar diferentes olhares para sua prática, atribuindo-lhe novos sentidos.

\section{Algumas considerações}

Por meio da análise dos enunciados dos docentes integrantes desta pesquisa podemos observar, no que diz respeito à formação necessária ao cooperante para atuação em Timor-Leste, a presença de lacunas que são percebidas e apontadas por esses sujeitos. O conhecimento da com- 
plexa situação linguística em Timor-Leste com foco específico para a necessidade de conhecimento pelo menos passivo de Tétum e/ou outra(s) língua(s) local(is) é fator determinante no desenvolvimento das atividades pedagógicas no país. Sendo assim, acentua-se a importância de cursos voltados ao estudo da língua que o aluno domina, no caso a língua tétum, para que haja uma troca rica de elementos linguísticos e culturais para ambos os lados.

Além disso, fez-se presente nos enunciados dos professores brasileiros a valoração positiva da formação docente específica voltada a aspectos metodológicos do ensino de língua não materna. Ou seja, ciência dos desafios e das diferenças que o ensino/ aprendizagem da língua materna e não materna trazem tanto aos alunos como aos professores. Tal reconhecimento sinaliza uma responsabilidade no agir pedagógico desses professores, que buscam a melhoria de sua prática, evitando assim uma transposição de ensino de LP como língua materna para os timorenses.

Considerando a relação intrínseca da língua com os elementos históricos-sociais de um povo, é imensamente importante o conhecimento da cultura e realidade timorense, já que, a língua como cultura constitui-se como diálogo entre culturas. Quando um professor reproduz a sua cultura e ignora a do sujeito que aprende, mesmo que de maneira não consciente, mantém o pensamento colonizador. Ensinar uma língua não materna é dialogar, ao mesmo tempo, com diferentes culturas. Um ensino que tenha essa premissa respeita e se integra à realidade do aluno e o motiva no aprendizado da nova língua. 


\section{TEACHER EDUCATION AND TEACHING OF PORTUGUESE IN EAST TIMOR: perceptions of Brazilian teachers}

\section{ABSTRACT}

In 2002, after the independence of the Democratic Republic of East Timor was restored, Portuguese and Tetum became official languages and media of instruction. As Portuguese was (re) introduced in the various social spheres of the country, Brazilian teachers from different fields of knowledge worked through the Teacher Education and Portuguese Language Teaching Program in East Timor (PQLP / CAPES). The teachers particularly devoted to teaching Portuguese were selected for this research. Data were collected through a questionnaire and consisted of written utterances about these teachers' education and teaching practices. The methodology used for data analysis was underpinned by the studies developed by Bakhtin $(2010 ; 2011)$. Based on the theory of dialogism, the following concepts (which compose the extraverbal context of the teachers' written production) were selected as categories of analysis of their utterances: the concepts of chronotope - (historical) time and (social) space - and valuejudgement, i.e., the subjects' social evaluation of the object referred to by their utterances. Overall, the analysis showed that there are gaps in the professional education of teachers who will work in East Timor; moreover, these teachers acknowledge the importance of relying on Tetum and aspects of Timorese culture while teaching Portuguese in this country.

KEYWORDS: Portuguese; East Timor; teaching; teacher education. 


\section{NOTAS}

${ }^{1}$ Disponível em: < http://pqlp.pro.br/introducao/> Acesso em: 18 de mar. de 2018.

\section{REFERÊNCIAS}

ALBUQUERQUE, Davi Borges. O ensino de Língua Portuguesa em Timor-Leste: variedades e dificuldades. Interdisciplinar. v. 12, p. 31-47, jul-dez, 2010.

ALMEIDA, Nuno C. 2012. "Para a (re)introdução da Língua Portuguesa em Timor- Leste" In: III SIMELP: A formação de novas gerações de falantes de português no mundo (Simpósio 37 - A Língua Portuguesa em Timor-Leste, pp. 29-42). Macau: Universidade de Macau.

ALMEIDA FILHO, José Carlos Paes. O Português como língua não-materna: concepções e contexto de ensino. Acervo digital do Museu da Língua Portuguesa. 2005. Acesso em 20 de abril de 2015. Disponível em $<\underline{\text { http://www.museudalin- }}$ guaportuguesa.org.br/files/mlp/texto_4.pdf $>$

ALMEIDA, Mário S. P. M. de; Ensino de português língua estrangeira - P. L. E. - língua global. Revista Virtual de Estudos da Linguagem - ReVEL. V. 2, n. 2, março de 2004, p. 1678-8931.

ANÇÃ, Maria Helena. "Da língua materna à língua segunda" In: Noesis. n. 51 julho/setembro, 1999. Disponível em: <http://area.dgidc.min- edu.pt/inovbasic/ edicoes/noe/noe51/dossier1.htm> Acesso em 19 de fevereiro de 2015.

BAKHTIN, Mikhail. Estética da criação verbal. $6^{\text {a }}$ ed. São Paulo: Martins Fontes, 2011, p. 261-306.

; (V. N. Volochínov). Marxismo e filosofia da linguagem. 14. ed. São Paulo: Hucitec, 2010.

CAPES, Coordenação de Aperfeiçoamento de Pessoal de Nível Superior. Programa de Qualificação de Docentes e Ensino de Língua Portuguesa no Timor-Leste - PQLP, Edital n. ${ }^{\circ}$ 76/2013. Recuperado de:<http://www.capes.gov.br/ images/stories/download/editais/Edital-076-2013-Timor- Leste-PQLP-31102013. pdf $>$ Acesso em junho de 2015.

MENDES, Edleise. "A ideia de cultura e sua atualidade para o ensino-aprendizagem de LE/L2” In: EntreLínguas, Araraquara, v.1, n.2, jul./dez. 2015, p. 203221.

PROJETO POLÍTICO PEDAGÓGICO do Programa de Qualificação de Docente em Língua Portuguesa em Timor-Leste (PQLP/CAPES). Disponível em: 
$<\underline{\text { http://pqlp.pro.br/wp-content/uploads/2015/05/Projeto-Pol\%C3\%ADtico- }}$ Pedag\%C3\%B3gico-PQLP.pdf $>$ Acesso em maio de junho de 2015.

SOARES, L. M. M. C. V. P. Línguas em Timor-Leste: que gestão escolar do plurilinguismo?, 561f. Tese (Doutorado em Educação), Departamento de Educação, Universidade de Aveiro, 2014.

TIMOR-LESTE. Lei n. ${ }^{\mathbf{0}} \mathbf{1 4} / \mathbf{2 0 0 8}$ de 29 de Outubro - Lei de Bases da Educação. Disponível em: $<$ http://www.jornal.gov.tl/?mod=artigo\&id=1453 $>$ Acesso em 23 de março de 2015.

VOLOCHÍNOV, Valentin; BAKHTIN, Mikhail. Palavra própria e palavra outra na sintaxe da enunciação. São Carlos: Pedro \& João Editores, 2011.

Recebido: 30/042018

Aceito: 14/09/2018 